\title{
Dynamics of Back Electron Transfer in Dye-Sensitized Solar Cells Featuring 4-tert-Butyl-Pyridine and Atomic-Layer-Deposited Alumina as Surface Modifiers
}

\author{
Michael J. Katz, ${ }^{\dagger}$ Michael J. DeVries Vermeer, ${ }^{\dagger \dagger}$ Omar K. Farha, ${ }^{\dagger, \S}$ Michael J. Pellin, ${ }^{\dagger, \ddagger}$ \\ and Joseph T. Hupp ${ }^{* \dagger, \ddagger, \|}$
} ${ }^{\dagger}$ Department of Chemistry and Argonne-Northwestern Solar Energy Research (ANSER) Center, Northwestern University, 2145
Sheridan Road, Evanston, Illinois 60208, United States
${ }^{\ddagger}$ Materials Science Division, Argonne National Laboratory, 9700 S. Cass Ave., Argonne, Illinois 60439, United States
${ }^{\S}$ Department of Chemistry, Faculty of Science, King Abdulaziz University, Jeddah, Saudi Arabia
${ }^{\|}$Chemical Sciences and Engineering Division, Argonne National Laboratory, 9700 S. Cass Ave., Argonne, Illinois 60439 , United
States

Supporting Information

ABSTRACT: A series of dye-sensitized solar cells (DSCs) was constructed with $\mathrm{TiO}_{2}$ nanoparticles and N719 dye. The standard $\mathrm{I}_{3}^{-} / \mathrm{I}^{-}$redox shuttle and the $\mathrm{Co}(1,10$-phenanthroline $)_{3}{ }^{3+/ 2+}$ shuttle were employed. DSCs were modified with atomic-layered-deposited (ALD) coatings of $\mathrm{Al}_{2} \mathrm{O}_{3}$ and/or with the surface-adsorbing additive 4-tert-butyl-pyridine. Currentvoltage data were collected to ascertain the influence of each modification upon the back electron transfer (ET) dynamics of the DSCs. The primary effect of the additives alone or in tandem is to increase the open-circuit voltage. A second is to alter the short-circuit current density, $J_{\mathrm{SC}}$. With dependence on the specifics of the system examined, any of a myriad of dynamics-related effects were observed to come into play, in

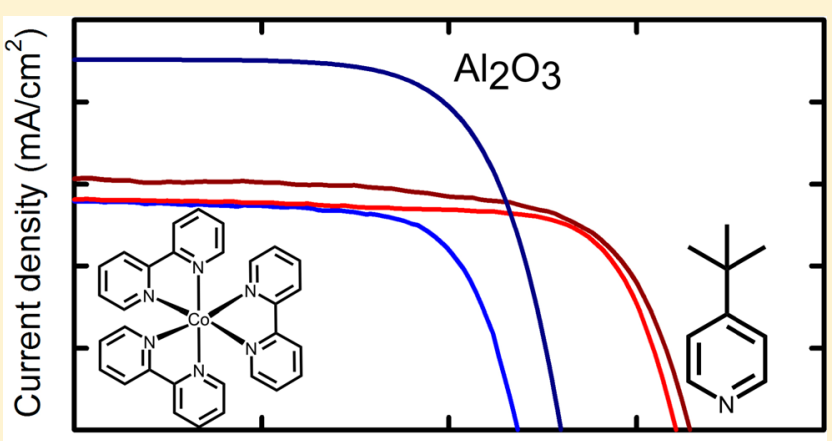

Potential (V) both favorable (efficiency boosting) and unfavorable (efficiency damaging) ways. These effects include modulation of (a) chargeinjection yields, (b) rates of interception of injected electrons by redox shuttles, and (c) rates of recombination of injected electrons with holes on surface-bound dyes. In turn, these influence charge-collection lengths, charge-collection yields, and onset potentials for undesired dark current. The microscopic origins of the effects appear to be related mainly to changes in driving force and/or electronic coupling for underlying component redox reactions. Perhaps surprisingly, only a minor role for modifierinduced shifts in conduction-band-edge energy was found. The combination of DSC-efficiency-relevant effects engendered by the modifiers was found to vary substantially as a function of the chemical identity of the redox shuttle employed. While types of modifiers are effective, a challenge going forward will be to construct systems in ways in which the benefits of organic and inorganic modifiers can be exploited in fully additive, or even synergistic, fashion.

\section{INTRODUCTION}

Energy conversion is initiated in molecular-dye-sensitized solar cells (DSCs) when chromophores bound to high surface area semiconductors are excited via light absorption. Excited electrons are injected into the semiconductor. The oxidized dye molecules are then regenerated by redox shuttles in solution. The injected electrons traverse the semiconductor network to the current collector, move to the external circuit, and ultimately reach the complementary form of the redox shuttle in the cell solution via a dark electrode. ${ }^{1-5}$

Since the introduction of high-surface-area photoelectrodes in $1991,{ }^{6}$ and the concomitant Beamon-esque leap ${ }^{7}$ in energy conversion efficiency (from less than $1 \%$ to ca. $7 \%$ ), a great deal of research has gone into both understanding what limits efficiencies and further improving efficiency. These efforts have included sizable investments in designing and creating new dyes, ${ }^{8,9}$ photoelectrode architectures, ${ }^{10}$ redox shuttles, ${ }^{11-17}$ interface modifications, ${ }^{18,19}$ and cell solution compositions. ${ }^{20}$ Among the largest contributors to efficiency loss in the bestexisting manifestations of DSCs are kinetic overpotentials for dye regeneration and for electron injection. For near-champion devices based on ruthenium dyes and the iodide/tri-iodide shuttle and operating at $11+\%,{ }^{21}$ nearly half of the theoretical

Special Issue: John R. Miller and Marshall D. Newton Festschrift

Received: June 18, 2014

Revised: August 14, 2014

Published: August 15, 2014 
maximum cell voltage (either the open-circuit photovoltage $\left(V_{\mathrm{oc}}\right)$ or the voltage at the maximum powerpoint) is lost to these processes. $^{21,22}$ Overpotential-related losses are similarly sizable for recently described dual-sensitizer cells operating at $12+\%$ and utilizing a cobalt-based redox shuttle. ${ }^{5}$

DSCs operate via a series of electron transfer (ET) processes, each of which must compete kinetically against an undesirable back-ET reaction or other process (for example, dye luminescence) that degrades photocurrent production. In a well-designed cell that mitigates against losses due to inefficient photon delivery (e.g., reflection losses, light harvesting, electron injection, dye regeneration, shuttle transport, and counterelectrode turnover of the redox shuttle), the maximum photocurrent density obtainable at short-circuit $\left(J_{S C-\max }\right)$ is determined by the ground-state/lowest-excited-state energy gap (roughly the HOMO/LUMO gap) of the dye, and the available solar flux at and above the gap. ${ }^{21}$ For the archetypal $\mathrm{Ru}$ dye, $\mathrm{N} 719$, this is about $18.4 \mathrm{~mA} / \mathrm{cm}^{2}$ at 1 sun (given a $90 \%$ incident-photon-to-current efficiency (IPCE), photon losses of ca. $15 \%$ in the visible region due to reflections and due to competitive absorption by the cell solution, and losses of up to $100 \%$ in the UV region due to competitive absorption by the current collector, typically a conductive oxide). However, if the dye is not regenerated quickly enough, or if diffusion of the redox shuttle is too slow, then $J_{\max }$ is further limited by the slower of these pathways, yielding $J^{\prime}{ }_{\max }{ }^{23}$ To complicate matters, if the injection efficiency $\left(\eta_{\text {inj }}\right)$ is not unity then photocurrents are further lowered (to $J^{\prime}{ }_{\max } \eta_{\text {inj }}$ ).

The short-circuit current density $\left(J_{\mathrm{SC}}\right)$, can thus be written as the forward photocurrent density $\left(J_{\text {max }}^{\prime} \eta_{\text {inj }}\right)$ plus the sum of the current densities due to detrimental (reverse) pathways $\left(J_{\text {det }}\right)$. The main rate processes contributing to $J_{\text {det }}$ are interception of electrochemically or photochemicaly injected electrons within the semiconductor by the oxidized form of the redox shuttle and back ET from the semiconductor to the oxidized dye. We term the first "electron interception" and the second "charge recombination." Notably, charge recombination occurs only under illumination; thus, its contributions are undetected by standard dark-current measurements. Equations 1 and 2 delineate how an illuminated cell's current density is affected by the various competing processes:

$$
\begin{aligned}
& J=J_{\max }^{\prime} \eta_{\text {inj }}+J_{\text {det }} \\
& J_{\text {det }}=J_{\text {interception }}+J_{\text {recombination }}
\end{aligned}
$$

$J_{\text {det }}$ which is oppositely signed to $J_{\max }$ typically is strongly potential-dependent. The potential at which it precisely offsets $J_{S C}{ }^{24}$ defines the DSC open-circuit photovoltage $\left(V_{\mathrm{OC}}\right)$. Consequently, cell modifications that diminish $J_{\text {det }}$ if unaccompanied by compensating effects upon $J^{\prime}{ }_{\max } \eta_{\text {inj }}$, will tend to increase $V_{\mathrm{OC}}$, and therefore, the overall DSC energyconversion efficiency, $\eta$.

Given these many processes, and their ability to simultaneously influence $J_{\mathrm{SC}}, V_{\mathrm{OC}}$, and fill factors, rational hypothesisdriven advances in DSC performance tend to require an understanding of rate dynamics at the various interfaces. ${ }^{25-28}$ Among the many interesting approaches to rate modification and DSC efficiency enhancement are (a) the addition of 4-tertbutyl-pyridine (TBP) to the cell solution (followed by its adsorption at the photoelectrode/solution interface $)^{29-33}$ and (b) the formation of ultrathin coatings of insulating and surface-state-passivating materials such as alumina. ${ }^{34-45}$ The former has been shown to boost values for $V_{\mathrm{OC}}$ by up to 340
$\mathrm{mV} .^{46}$ The latter is capable, in extreme cases, of increasing $V_{\mathrm{OC}}$ by as much as $390 \mathrm{mV},{ }^{47}$ albeit often with offsetting decreases in photocurrent density. One interpretation of the voltage boosts is that additives (of both kinds) shift the conduction band edge of the photoelectrode in the negative electrochemical direction, thereby engendering equivalent negative shifts in the photoelectrode's quasi-Fermi level under conditions of open-circuit illumination. ${ }^{48-50}$

We recently investigated the roles of added TBP and atomiclayer deposited (ALD) alumina in altering specifically the rates and dynamics of electron-interception (i.e., capture of injected electrons by the oxidized form of the redox shuttle). We probed the effects mainly by evaluating dark currents. We observed that both modifiers suppress potential-dependent dark currents, and further, that the suppression effects are roughly additive. ${ }^{51}$ To our surprise, however, TBP and ALD alumina were found to influence $J_{\text {interception }}$ by mechanisms other than shifts in conduction-band-edge energy $\left(E_{\mathrm{cb}}\right)$. Indeed, despite anticipated energy contributions from preferential orientation of molecular dipoles and other phenomena, ${ }^{48-50} E_{\mathrm{cb}}$ was found to be only slightly changed (a few tens of millivolts or less) by addition of either substance to the electrode/solution interface, as demonstrated by Mott-Schottky measurements of flat-band potentials $\left(E_{\mathrm{fb}}\right)^{51}$

These earlier studies were done with simplified and experimentally idealized systems (i.e., well-defined, ALDfabricated, flat $\mathrm{TiO}_{2}$ electrodes) and were limited to darkcurrent investigations at dye-free interfaces. Here we extend the studies to high-area nanoparticulate photoelectrodes, and we employ the electrodes, with dye coatings and under illumination, in fully assembled cells. We utilize $\mathrm{I}_{3}{ }^{-} / \mathrm{I}^{-}$and $\mathrm{Co}(\text { phen })_{3}^{3+/ 2+}$ as redox shuttles (phen $=1,10$-phenanthroline). We find that in addition to modulating electron interception, the organic and inorganic surface modifiers alter both charge-injection yields and rates for charge recombination. The importance of the latter, in terms of changes in DSC performance, is found to depend strongly on the chemical identity of the redox shuttle employed.

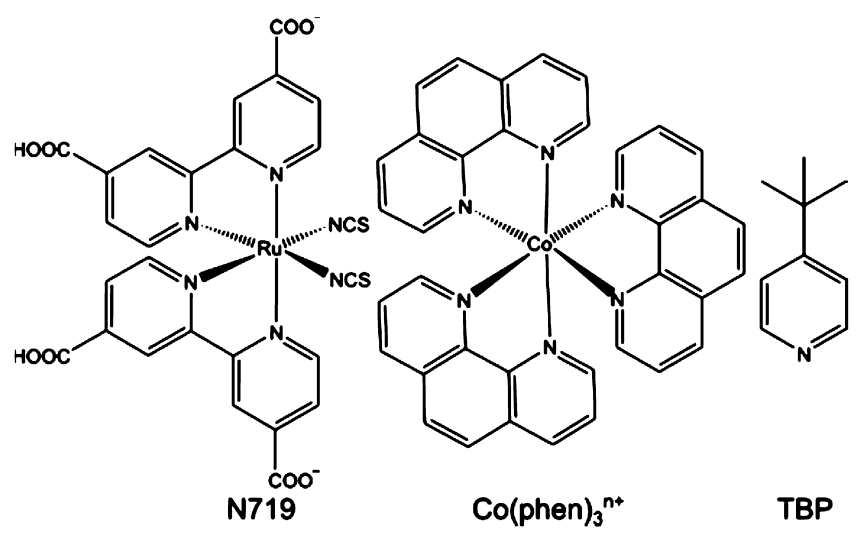

\section{EXPERIMENTAL SECTION}

Unless otherwise indicated, all reagents were purchased from commercial sources and used without further purification. Both 8 and $15 \Omega \mathrm{cm}^{-2}$ fluorine-doped tin oxide (FTO) glass were purchased from Hartford Glass. $\left[\mathrm{Co}(\mathrm{phen})_{3}\right]\left(\mathrm{PF}_{6}\right)_{2}$, $\left[\mathrm{Co}(\text { phen })_{3}\right]\left(\mathrm{PF}_{6}\right)_{3}$, (phen $=1,10$-phenantrholine $)$ were made according to literature procedures; briefly, $\mathrm{Co}\left(\mathrm{NO}_{3}\right)_{2} \cdot\left(\mathrm{H}_{2} \mathrm{O}\right)_{6}$ was dissolved in a minimum amount of methanol. To the reaction mixture was added 3.3 equiv of phen, likewise 
dissolved in a minimum amount of methanol. A ca. 10-fold excess of $\mathrm{NH}_{4} \mathrm{PF}_{6}$ was added to the reaction mixture. The Co shuttle was then precipitated by addition of water. Oxidation of $\mathrm{Co}(\mathrm{II})$ to $\mathrm{Co}(\mathrm{III})$ was carried out with $\mathrm{NOBF}_{4}$ in $\mathrm{CH}_{3} \mathrm{CN}$ and isolated via the addition of $\mathrm{NH}_{4} \mathrm{PF}_{6}$, followed by water.

All electrolyte shuttles solutions were prepared in acetonitrile by mixing $0.02 \mathrm{M}$ of the oxidized form (i.e., $\mathrm{Co}(\mathrm{III})$ or $\mathrm{I}_{3}{ }^{-}$), 0.2 $\mathrm{M}$ of the reduced form (i.e., $\mathrm{Co}(\mathrm{II})$ or $\mathrm{I}^{-}$), and $0.2 \mathrm{M} \mathrm{LiClO}_{4}$. In some cells, $0.2 \mathrm{M}$ 4-tert-butyl-pyridine was also included.

2.1. Electrode Preparation. Photoanodes were prepared on $8 \Omega \mathrm{cm}^{-2}$ FTO glass. $1.5 \times 1.5 \mathrm{~cm}$ Squares were cut and then sonicated in water with detergent for $15 \mathrm{~min}$. The samples were rinsed with deionized water and then sonicated in isopropanol for $15 \mathrm{~min}$, followed by methanol for an additional $15 \mathrm{~min}$. After air drying, the electrodes were heated to $500{ }^{\circ} \mathrm{C}$ for $1 \mathrm{~h}$ with the aim of removing organic residues.

Counter electrodes were prepared on $15 \Omega \mathrm{cm}^{-2}$ FTO glass. $2.0 \times 2.0 \mathrm{~cm}$ Squares, each with one hole drilled, were cleaned in an identical manner to the photoanodes. The clean counter electrodes were evenly coated with $13 \mu \mathrm{L}$ of a $0.5 \mathrm{mM}$ isopropanol solution of $\mathrm{H}_{2} \mathrm{PtCl}_{6}$ and then placed in an oven at $500{ }^{\circ} \mathrm{C}$ for $30 \mathrm{~min}$ to produce the platinum-coated counter electrode.

A ca. $10 \mathrm{~nm}$ blocking layer of $\mathrm{TiO}_{2}$ was grown on the electrode via atomic layer deposition (Savannah 100 reactor, Cambridge Nanotech, Inc.) using alternating half-cycles of titanium isopropoxide $(0.1 \mathrm{~s}$ pulse, $1 \mathrm{~s}$ exposure, $10 \mathrm{~s}$ nitrogen purge) and water (0.1 s pulse, $1 \mathrm{~s}$ exposure, $15 \mathrm{~s}$ nitrogen purge). Three-hundred full cycles were used. The reactor temperature was maintained at $200{ }^{\circ} \mathrm{C}$. The prepared films were then heated at $475{ }^{\circ} \mathrm{C}$ for $6 \mathrm{~h}$.

$\mathrm{TiO}_{2}$ nanoparticles (Dyesol) were doctor-bladed onto the electrode through a $0.25 \mathrm{~cm}^{2}$ hole in a piece of scotch tape. The films were then placed in an oven at $80{ }^{\circ} \mathrm{C}$. The tape was removed, and the films were annealed at $450{ }^{\circ} \mathrm{C}$ over the course of $6 \mathrm{~h}$. The annealed films were ca. $6 \mu \mathrm{m}$ thick.

Alumina-coated $\mathrm{TiO}_{2}$ films were prepared by ALD-coating the annealed $\mathrm{TiO}_{2}$ films using 1 cycle of trimethyl aluminum (0.03 s pulse, $1 \mathrm{~s}$ exposure, $30 \mathrm{~s}$ purge) and deionized water (0.1 s pulse, $1 \mathrm{~s}$ exposure, and $30 \mathrm{~s}$ purge). One ALD cycle results in formation of roughly one-third of a monolayer of alumina. ALD conditions were chosen to uniformly coat all $\mathrm{TiO}_{2}$ surfaces of the doctor-bladed nanoparticle films.

Films were dye-soaked overnight in a $0.5 \mathrm{mM}$ ethanolic solution of N719 \{Dysol; N719: $\left(\mathrm{Bu}_{4} \mathrm{~N}\right)_{2}\left[\mathrm{Ru}(\mathrm{dcbp})_{2}(\mathrm{NCS})_{2}\right]$ $\left(\mathrm{dcbp}=4,4^{\prime}\right.$-dicarboxy-2,2'-bipyridine $\left.)\right\}$. They were subsequently rinsed with ethanol to remove unattached dye.

The photo- and counter-electrode were sandwiched together by melting a $25 \mu \mathrm{m}$ thick piece of Surlyn, having a hole slightly larger than the diameter of the photoanode, between the two electrodes. The edge of the photoanode was sanded and silver epoxy was spread over the edge in order to form a good electrical contact with the FTO.

Electrolyte solution was vacuum backfilled into the cell via capillary forces through a drilled hole in the counter electrode. The hole was then sealed by melting a second piece of Surlyn over the counter electrode.

2.2. Electrochemical Measurements. Photoelectrochemical measurements were carried out with a Solartron "Analytical Modulab” instrument equipped with a $1 \mathrm{MHz}$ frequency analyzer and a potentiostat capable of measuring 1 million samples/second interfaced with a Horiba FluoroLog-3 fluorometer equipped with a $450 \mathrm{~W}$ ozone-free xenon lamp.
The fluorometer slit width and sample holder were positioned so as to set light intensity to $100 \mathrm{~mW} \mathrm{~cm}^{-2}$ after passing through an AM1.5 solar filter.

\section{RESULTS}

3.1. J-V Curves under Illumination. Plots of photocurrent-density versus cell voltage $(J-V$ plots) are shown in Figure 1. Independent of surface modifier, values for $J_{S C}$ were

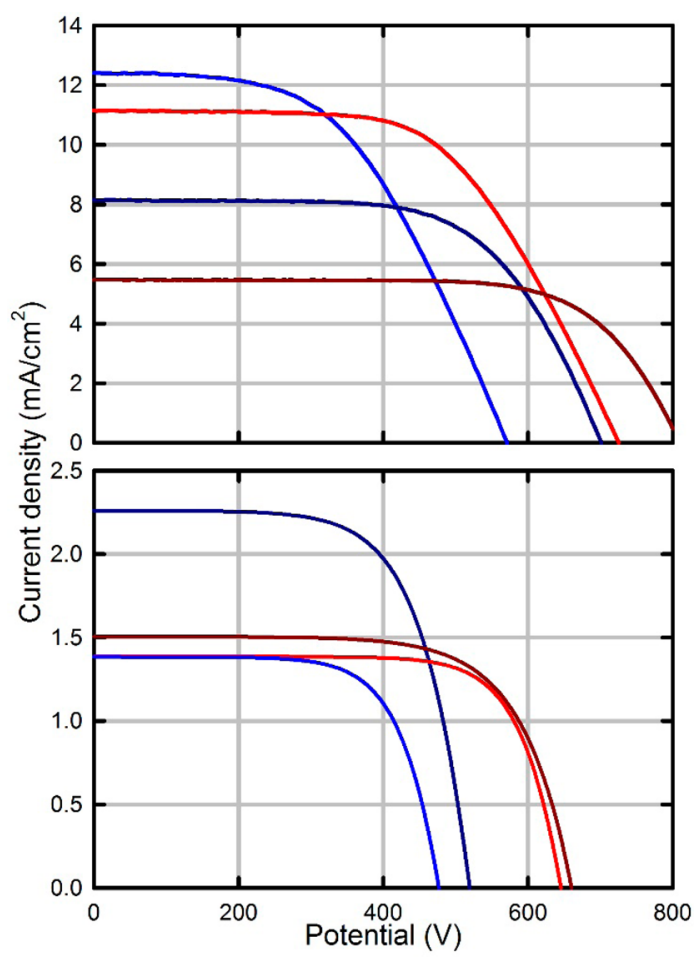

Figure 1. Current vs voltage plots of DSCs containing, $\mathrm{I}_{3}^{-} / \mathrm{I}^{-}$(top) and $\mathrm{Co}$ (phen) ${ }_{3}{ }^{3+/ 2+}$ (bottom). Blue: no modifier; red: TBP; dark blue: $\mathrm{Al}_{2} \mathrm{O}_{3}$; brown: TBP and $\mathrm{Al}_{2} \mathrm{O}_{3}$.

lower for cells containing $\mathrm{Co}(\mathrm{phen}) 3^{3+/ 2+}$ than for cells containing $\mathrm{I}_{3}^{-} / \mathrm{I}^{-}$. For $\mathrm{I}_{3}^{-} / \mathrm{I}^{-}, J_{\mathrm{SC}}$ decreases in the order of $J_{\text {SC }}($ no modifier $)>J_{\text {SC }}($ TBP $)>J_{\text {SC }}\left(\mathrm{Al}_{2} \mathrm{O}_{3}\right)>J_{\text {SC }}\left(\mathrm{Al}_{2} \mathrm{O}_{3}\right.$ and TBP); the modifiers only decreased the observed photocurrents. However, for $\mathrm{Co}$ (phen) $3^{3+/ 2+}$, ALD alumina boosted $J_{\mathrm{SC}}$ by ca. $65 \%$, whereas introduction of TBP had no effect upon $J_{\mathrm{SC}}$. Curiously, the inclusion of both modifiers with Co(phen $)_{3}^{3+/ 2+}$ yielded current that were only $15 \%$ higher than the modifier-free devices.

Independent of the redox shuttle employed, open-circuit photovoltages were ordered as follows: $V_{\mathrm{OC}}$ (no modifier) < $V_{\mathrm{OC}}\left(\mathrm{Al}_{2} \mathrm{O}_{3}\right)<V_{\mathrm{OC}}(\mathrm{TBP})<V_{\mathrm{OC}}\left(\mathrm{Al}_{2} \mathrm{O}_{3}\right.$ and TBP $)$. The maximum voltage increases (i.e., those obtained by combining modifiers) were ca. $220 \mathrm{mV}$.

For $\mathrm{I}_{3}{ }^{-} / \mathrm{I}^{-}$-containing cells, the overall energy conversion efficiency $(\eta)$ is largest when just TBP is employed as the modifier. Despite the increased $V_{\mathrm{OC}}$ when $\mathrm{Al}_{2} \mathrm{O}_{3}$ is employed (either alone or in tandem with TBP), the overall efficiency decreases due to decreases in $J_{\mathrm{SC}}$. When $\mathrm{Co}$ (phen) $3_{3}{ }^{3+/ 2+}$ was used, $\eta$ was lowest for modifier-free cells. By increasing $V_{\mathrm{OC}}$ by ca. $200 \mathrm{mV}$, TBP increases the overall efficiency. The efficiencies of cells modified with $\mathrm{Al}_{2} \mathrm{O}_{3}$ are maximal. However, when both $\mathrm{Al}_{2} \mathrm{O}_{3}$ and TBP are employed, the efficiencies are only slightly higher than devices modified only with TBP; the 
increase in $V_{\mathrm{OC}}$ in DSCs containing both $\mathrm{Al}_{2} \mathrm{O}_{3}$ and TBP is offset by the decrease in the $J_{\mathrm{SC}}$ relative to the DSCs modified only with $\mathrm{Al}_{2} \mathrm{O}_{3}$.

3.2. Dark $J-V$ Curves. Figure 2 shows the dark $J-V$ responses for DSCs containing either $\mathrm{I}_{3}{ }^{-} / \mathrm{I}^{-}$or $\mathrm{Co}(\text { phen })_{3}{ }^{3+/ 2+}$,

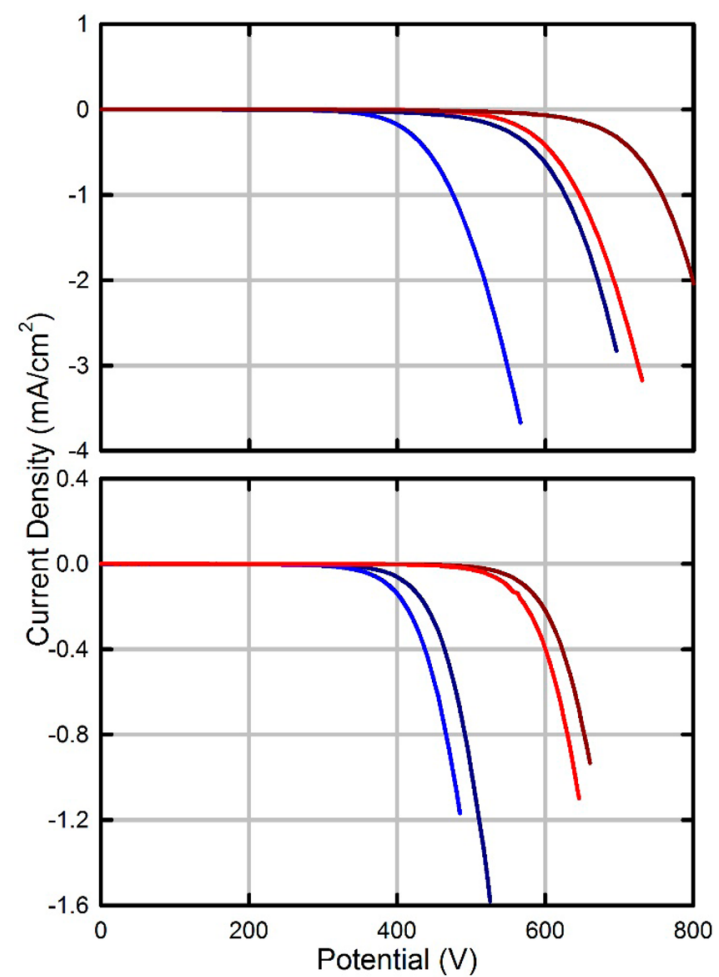

Figure 2. Plots of dark current vs voltage of DSCs containing $\mathrm{I}_{3}^{-} / \mathrm{I}^{-}$ (top) and $\mathrm{Co}$ (phen) $3^{3+/ 2+}$ (bottom). Blue: no modifier; red: TBP; dark blue: $\mathrm{Al}_{2} \mathrm{O}_{3}$; brown: TBP and $\mathrm{Al}_{2} \mathrm{O}_{3}$.

with and without electrode surface modifiers. The dark currents are plotted out to the value of $V_{\mathrm{OC}}$ for the corresponding illuminated systems. ${ }^{52}$ Briefly, for both shuttles, both modifiers serve to suppress dark current (or stated differently, both serve to inhibit shuttle interception of electrochemically injected electrons). When the modifiers are used in tandem, partially additive changes in the potential for onset of dark current are observed. Clearly, suppression of dark current provides a reasonable qualitative accounting of the effects of modifiers upon open-circuit photovoltages (although, as detailed below, additional factors contribute).

3.3. Charge-Collection Lengths. Electrons generated near the back of the dye-coated electrode (for example, by illuminating the photoelectrode through the solution) obviously travel farther to reach the current collector than those supplied near the front of the electrode (for example, by illumination of the photoelectrode through the transparent conducting oxide support, for instance, the current collector). Thus, ratios of IPCE values for back-side versus front-side illumination report on the charge collection length within the film. Qualitatively, the more similar the two plots, the larger the photoelectrode's charge collection length. ${ }^{53}$ For DSCs containing $\mathrm{Co}(\mathrm{phen})_{3}{ }^{3+/ 2+}$ as the redox species, the plots diverge greatly. The maximum IPCE values with this shuttle are $12 \%$ with front-side illumination and just $2 \%$ with back-side illumination ( $3 \%$ with TBP). For comparison, an otherwise similar $\mathrm{I}_{3}^{-} / \mathrm{I}^{-}$cell exhibited a maximum IPCE of $70 \%$ with front-side illumination and $50 \%$ with back-side illumination (i.e., a ratio of 0.7). ${ }^{54}$ The plots indicate that the charge collection length is (a) relatively short (Figure 3, top) when compared with $\mathrm{I}_{3}{ }^{-} / \mathrm{I}^{-}$-containing DSCs (see Figure $\mathrm{S} 1$ of the Supporting Information), and (b) only marginally increased by adding $t$-butyl-pyridine.

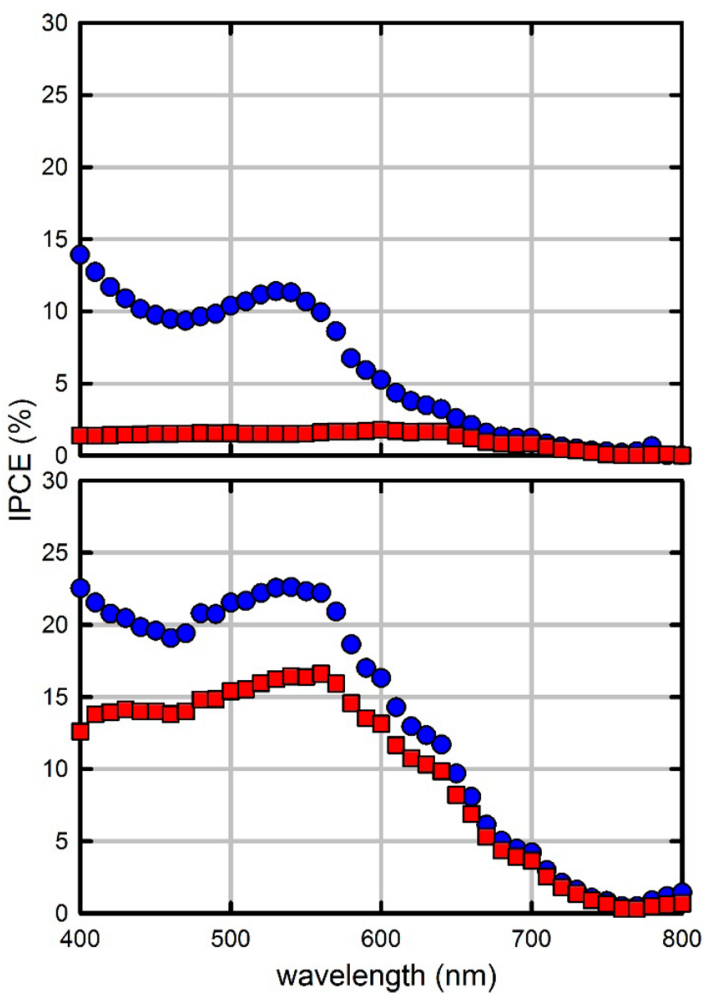

Figure 3. Front side (blue $\mathbf{0}$ ) and back side (red $\mathbf{0}$ ) IPCEs of $\mathrm{Co}$ (phen) $3^{3+/ 2+}$-containing DSCs. TBP (top) and $\mathrm{Al}_{2} \mathrm{O}_{3}$-free DSCs. $\mathrm{Al}_{2} \mathrm{O}_{3}$-coated photoanode (bottom); see Figure $\mathrm{S} 1$ of the Supporting Information for front- and back-side IPCEs of $\mathrm{I}_{3}{ }^{-} / \mathrm{I}^{-}$.

Returning to DSCs employing $\mathrm{Co}$ (phen) $3^{3+/ 2+}$ as the redox shuttle, we find that photoelectrode modification with ALD $\mathrm{Al}_{2} \mathrm{O}_{3}$ greatly enhances IPCE values. The maximum for frontside illumination increases from a peak of $12 \%$ to nearly $25 \%$, while for back-side illumination the peak value increases from a meager $2 \%$ to $15 \%$ (Figure 3, bottom). ${ }^{55}$ More importantly, in terms of effects of modifiers on charge-collection lengths, the ratio of IPCE maxima increases from $\sim 0.17$ to 0.6 . Thus, ALD modification boosts the current output of DSCs that use $\mathrm{Co}$ (phen $3_{3}{ }^{3+/ 2+}$ largely by boosting the photoelectrode's charge-collection length.

3.4. Overall Efficiencies. Overall energy conversion efficiencies for the various DSCs, calculated from fill-factors and the parameters discussed above, are summarized in Table 1. As noted above, to facilitate assessment of the effects, while avoiding complications from light scattering, nonoptimized cells were used [i.e., thin $(6 \mu \mathrm{m})$ anodes, no scattering layer, and no $\mathrm{TiCl}_{4}$ treatment]. On the basis of the light-harvesting efficiency data in Figure 4, the maximum photocurrent possible for anodes described herein is ca. $13 \mathrm{~mA} / \mathrm{cm}^{2}$. The highest $V_{\mathrm{OC}}$ value obtained is $820 \mathrm{mV}$, which is comparable to the highest observed with champion or near-champion, N719-based cells. ${ }^{56}$ The highest fill factor in Table 1 (albeit, for a different cell) is 0.74 ; the value is slightly below what has been reported for fully 
Table 1. Summary of Photoelectrochemical Data for DSCs Containing Organic and/or Inorganic Surface Modifiers

\begin{tabular}{lrrrrc} 
& $\begin{array}{c}J_{\mathrm{SC}} \\
\left(\mathrm{mA} / \mathrm{cm}^{2}\right)\end{array}$ & $\begin{array}{c}V_{\mathrm{OC}} \\
(\mathrm{mV})\end{array}$ & FF & $\eta(\%)$ & $\begin{array}{c}J_{\text {interception }} \\
\left(\mathrm{mA} / \mathrm{cm}^{2}\right)\end{array}$ \\
$\mathrm{I}_{3}{ }^{-} / \mathrm{I}^{-}$ & & & & & \\
none & 12.4 & 570 & 0.51 & 3.6 & -3.7 \\
$\mathrm{TBP}$ & 11.2 & 730 & 0.58 & 4.7 & -3.2 \\
$\mathrm{Al}_{2} \mathrm{O}_{3}$ & 8.1 & 700 & 0.64 & 3.6 & -2.8 \\
$\mathrm{TBP}$ and $\mathrm{Al}_{2} \mathrm{O}_{3}$ & 5.5 & 820 & 0.70 & 3.1 & -2.6 \\
$\mathrm{Co}(\text { phen })_{3}{ }^{3+2+}$ & & & & & \\
none & 1.4 & 490 & 0.68 & 0.46 & -1.2 \\
$\mathrm{TBP}$ & 1.4 & 650 & 0.74 & 0.67 & -1.0 \\
$\mathrm{Al}_{2} \mathrm{O}_{3}$ & 2.3 & 530 & 0.67 & 0.80 & -1.6 \\
$\mathrm{TBP}$ and $\mathrm{Al}_{2} \mathrm{O}_{3}$ & 1.6 & 660 & 0.68 & 0.70 & -0.84 \\
\hline
\end{tabular}

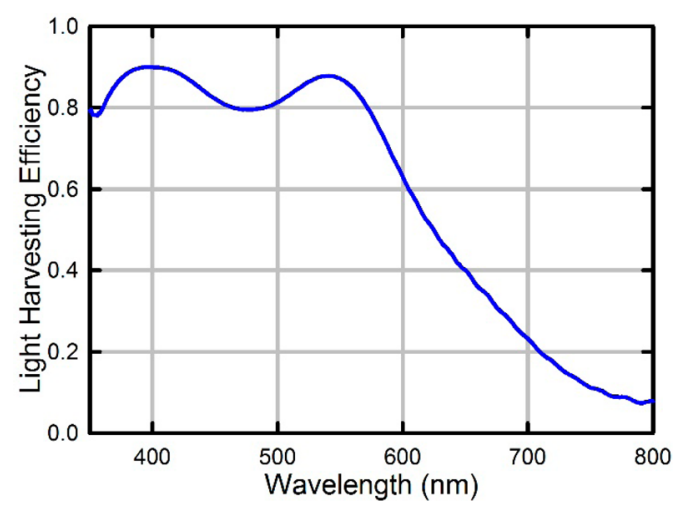

Figure 4. Apparent light-harvesting efficiency for a $6 \mu \mathrm{m}$ thick photoanode featuring a monolayer of adsorbed N719. The plot is uncorrected for light-scattering contributions in the corresponding optical extinction measurements and this accounts for the seemingly nonzero light-harvesting efficiency between 750 and $800 \mathrm{~nm}$.

optimized, N719-based DSCs. ${ }^{56}$ If these individually maximized parameters could be simultaneously expressed in a single cell, the highest efficiency we might expect for a N719-based DSC containing an interface-modified photoelectrode, simplified as described above, would be $7.4 \%$. The highest efficiency found experimentally for our interface-modified cells is only $4.7 \%$ points, in particular, to the difficulty in enhancing charge collection length without sacrificing injection efficiency.

\section{DISCUSSION}

4.1. Triiodide/lodide-Containing DSCs. The $\mathrm{I}_{3}^{-} / \mathrm{I}^{-}$ redox couple is unparalleled for Ru-sensitized cells because devices incorporating this couple have electron collection lengths exceeding the thicknesses of typically employed photoanodes. ${ }^{57}$ Thus, it is not surprising that the observed $J_{\mathrm{SC}}$ value for DSCs lacking modifiers (i.e., $12.4 \mathrm{~mA} / \mathrm{cm}^{2}$ ) is nearly as great as the maximum value anticipated based on the light-harvesting efficiency. From the near agreement, we conclude that under the conditions of our experiments, the charge-injection efficiency is close to unity.

Electrode surface modification with TBP significantly decreases dark currents (suppresses $J_{\text {interception}}$ ), leading to the observed $160 \mathrm{mV}$ increase in $V_{\mathrm{OC}}$, in good agreement with previous work. $^{29}$ For $J_{\mathrm{SC}}$, in contrast, the addition of TBP engenders a slight decrease. As noted above, charge-collection lengths are large for DSCs that use $\mathrm{I}_{3}{ }^{-} / \mathrm{I}^{-}$, implying that at short-circuit, the charge-collection efficiency, $\eta_{\text {coll }}$ is close to unity. Suppressing $J_{\text {interception }}$ (via TBP addition) can only improve $\eta_{\text {coll }}$ and enhance $J_{\text {SC }}$.

Rather than enhancing $\eta_{\text {coll }}$, we believe that TBP lowers the short-circuit current density by decreasing the charge-injection yield, $\eta_{\text {inj. }}$ The yield is determined by the kinetics of electron injection relative to the kinetics for competing dye-excited-state relaxation processes. The rate of electron injection is sensitive to the strength of the donor/acceptor (excited-dye $/ \mathrm{TiO}_{2}$ electrode) electronic coupling and to the ET driving force. The organic modifier is unlikely to influence electronic coupling significantly, but it could lower the driving force for injection by shifting $E_{\mathrm{cb}}$ to higher energy (more negative electrochemical potential). We have shown elsewhere, in studies with nonporous $\mathrm{TiO}_{2}$ electrodes, that addition of TBP (or ALD alumina) shifts $E_{\mathrm{cb}}$ by, at most, a few tens of millivolts. ${ }^{51}$ While a shift of this magnitude is inconsequential in terms of direct effects on open-circuit photovoltages, it could be enough to slow the rate of electron injection by as much as 2fold. ${ }^{58}$ In turn, the injection yield for an otherwise optimized dye/semiconductor pair could drop by several percent or more.

The effects on $J_{\mathrm{SC}}$ and $V_{\mathrm{OC}}$ of electrode modification with alumina are similar to those arising from TBP addition, and we assume that the causes are similar. Previous work by Antilla et al. ${ }^{41,42}$ strongly supports the notion that even small amounts of ALD alumina can lower injection yields sufficiently to substantially degrade short-circuit current densities. ${ }^{59}$

From eq 1, an alternative or additional explanation for the modifier-induced decreases in $J_{\mathrm{SC}}$ would be increases in

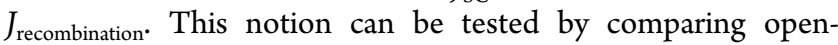
circuit photovoltage decays (OCPVD) with open-circuit voltage decays (OCVD; dark decays), since charge recombination can influence only the former. The observed close agreement of decay data for the two types of experiments (Figure 5) shows that for iodide-based cells, $J_{\text {recombination }}$ is not a significant contributor to $J_{\text {det }}{ }^{60}$

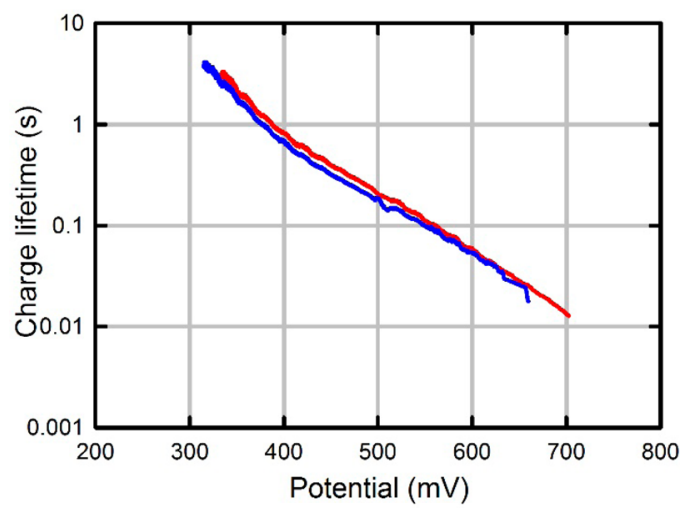

Figure 5. Comparison of open-circuit photovoltage decay (OCPVD) and open-circuit voltage decay (OCVD) measurements for DSCs containing $\mathrm{I}_{3}^{-} / \mathrm{I}^{-}$as the redox shuttle (no $\mathrm{Al}_{2} \mathrm{O}_{3}$ or TBP coatings). Blue: OCPVD; red: OCVD.

4.2. Co(phen) $3^{3+/ 2+}$-Containing DSCs. $J_{S C}$ values for $\mathrm{Co}$ (phen) $3^{3+/ 2+}$-containing DSCs are smaller than those observed in $\mathrm{I}_{3}{ }^{-} / \mathrm{I}^{-}$. As discussed above, for modifier-free DSCs the difference clearly is due to much less efficient charge collection when $\mathrm{Co}$ (phen $)_{3}{ }^{3+/ 2+}$ is the redox shuttle. From front-side/back-side IPCE measurements, the inorganic modifier significantly increases the charge-collection length, while the organic modifier has little effect on the collection 
length (Figure 3; front-side/back-side illumination is nearly identical for TBP/TBP-free DSCs). Indeed, the chargecollection length with alumina-modified photoelectrodes approaches the thickness of the electrode itself. Nevertheless, $J_{S C}$ reaches only about a quarter of the value anticipated for cells displaying both high injection yields and high chargecollection efficiencies. However, a different trend in current/ voltage changes is observed; when TBP is used, only $V_{\mathrm{OC}}$ is significantly altered due to the suppression of $J_{\text {interception }}$ (Figure 2). Comparison of OCPVD and OCVD (Figure 6 and Figure

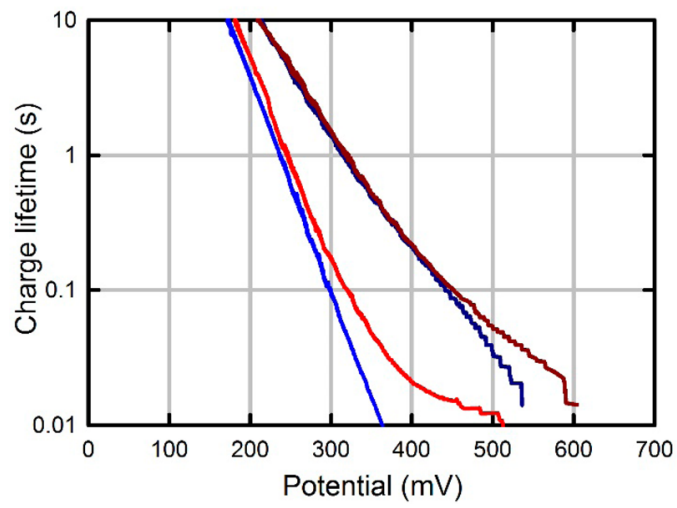

Figure 6. Comparison of open-circuit photovoltage decay (OCPVD) and open-circuit voltage decay (OCVD) measurements for DSCs containing $\mathrm{Co}($ phen $) 3^{3+/ 2+}$ as the redox shuttle. Blue: OCPVD; red: OCVD; dark blue: OCPVD with $\mathrm{Al}_{2} \mathrm{O}_{3}$; brown: OCVD with $\mathrm{Al}_{2} \mathrm{O}_{3}$. See Figure $\mathrm{S} 2$ of the Supporting Information for TBP-containing OCPVD/OCVD plots.

$\mathrm{S} 2$ of the Supporting Information) illustrates that when $\mathrm{Al}_{2} \mathrm{O}_{3}$ is coated on the photoanode, the two plots look nearly identical, indicating that $J_{\text {recombination }}$ is not a significant contribution to $J_{\text {dark }}$ (eq 2). However, when no $\mathrm{Al}_{2} \mathrm{O}_{3}$ is present then the two plots differ at high potentials, indicating that the oxidized dye is not being regenerated fast enough by $\mathrm{Co}(\text { phen })_{3}{ }^{2+}$, and thus there exists a significant contribution to $J_{\operatorname{det}}$ from $J_{\text {recombination }}$ (eq 2).

Since the modifiers act in distinctly different ways, it seemed possible that their combination might yield an additive advantage. Unfortunately, when both modifiers are used, $J_{\mathrm{SC}}$ decreases; the undesirable decrease in charge-injection yield more than offsets the beneficial effects of suppressing $J_{\text {interception }}$ and $J_{\text {recombination }}$.

\section{CONCLUSIONS}

The performance of dye-sensitized solar cells constructed with either $\mathrm{Co}$ (phen $)_{3}{ }^{3+2+}$ or $\mathrm{I}_{3}{ }^{-} / \mathrm{I}^{-}$as the redox shuttle and utilizing simplified photoanode structures (i.e., thin electrodes, no $\mathrm{TiCl}_{4}$ treatment, no scattering layer) can be affected in a variety of ways, both favorable and unfavorable, by introduction of an organic surface-modifier (4-tert-butyl-pyridine), an inorganic surface-modifier ( $\mathrm{ALD}$-deposited $\mathrm{Al}_{2} \mathrm{O}_{3}$ ), or both. We find that for DSCs that are capable of quantitatively collecting photogenerated charges at short-circuit (i.e., those using $\mathrm{I}_{3}^{-} / \mathrm{I}^{-}$), added TBP boosts energy-conversion efficiencies by slowing electron interception and thereby increasing cell photovoltages. When surface modification instead consists of ALD $\mathrm{Al}_{2} \mathrm{O}_{3}$ or the combination of $\mathrm{Al}_{2} \mathrm{O}_{3}$ and TBP, photovoltages are again increased, but the gains are more than offset by decreases in photocurrent due to decreases in charge- injection yield. The latter are traceable to small shifts in the conduction band-edge toward more negative electrode potential shifts that should decrease the thermodynamic driving force for dye injection.

For cells containing $\mathrm{Co}$ (phen) $3^{3+/ 2+}$ as the redox shuttle, charge collection is comparatively inefficient. Photoelectrode treatment with ALD alumina, either in isolation or in tandem with TBP, favorably influences cell efficiencies by increasing both $J_{\mathrm{SC}}$ and $V_{\mathrm{OC}}$. The basis for increasing $J_{\mathrm{SC}}$ is mainly by suppressing losses due to electron recombination with the oxidized dye, with secondary contributions due to decreases in rates of interception of injected electrons by the oxidized form of the shuttle. Addition of TBP to a device both suppresses charge-interception and, at least with electrodes that are also ALD-modified, decreases the charge-injection yield. These opposing effects account for the inability of TBP to improve the overall efficiency in nonoptimized DSCs when alumina is already present. With $\mathrm{I}_{3}^{-} / \mathrm{I}^{-}$, ALD-alumina treatment boosts $V_{\mathrm{OC}}$ both by boosting $J_{\mathrm{SC}}$ and by suppressing dark current (i.e., slowing electron interception). In contrast, with Co(phen $)_{3}^{3+/ 2+}$, ALD-alumina boosts $V_{\mathrm{OC}}$ by decreasing charge-recombination to the dye and thereby increasing $J_{\mathrm{SC}}$. This interpretation is supported by OCVD versus OCPVD experiments. When $\mathrm{Co}$ (phen) $3^{3+/ 2+}$ is used, the combination of the two surface modifiers notably outperforms cells that contain only the organic modifier. In summary, surface modifiers influence not only rates of back electron transfer (both to the redox shuttle and the oxidized dye) but also rates of charge injection (more so for TBP than ALD alumina). Although TBP engenders slightly greater voltages in DSCs than does the inorganic modifier, the latter increases charge-collection lengths and enhances $J_{\mathrm{SC}}$, sufficiently making it the preferred option when comparatively thick photoelectrodes are used in combination with cobalt-based redox shuttles.

\section{ASSOCIATED CONTENT}

\section{S Supporting Information}

Incident photon-to-current efficiency for iodide/triiodidecontaining DSCs and open-circuit voltage/photovoltage decay of $\mathrm{Co}($ phen $){ }_{3}{ }^{3+2+}$ and TBP-containing DSCs. This material is available free of charge via the Internet at http://pubs.acs.org.

\section{AUTHOR INFORMATION}

\section{Corresponding Author}

*E-mail: j-hupp@northwestern.edu. Fax: +1-847-467-1425. Tel: +1-847-491-3504.

\section{Author Contributions}

The manuscript was written through contributions of all authors. All authors have given approval to the final version of the manuscript.

\section{Notes}

The authors declare no competing financial interest.

\section{ACKNOWLEDGMENTS}

J.T.H. gratefully acknowledges many enlightening discussions with both Marshal Newton and John Miller about electrontransfer phenomena and thanks them for sharing their extraordinary insights and for publishing their many groundbreaking findings. We gratefully acknowledge the ANSER Center, an Energy Frontier Research Center funded by the U.S. Department of Energy, Office of Science, Office of Basic Energy 
Sciences under Award Number DE-SC0001059 for support of our work.

\section{REFERENCES}

(1) Grätzel, M. Recent Advances in Sensitized Mesoscopic Solar. Acc. Chem. Res. 2009, 42, 1788-1798.

(2) Yanagida, S.; Yu, Y.; Manseki, K. Iodine/Iodide-Free DyeSensitized Solar Cells. Acc. Chem. Res. 2009, 42, 1827-1838.

(3) Nelson, J. The Physics of Solar Cells; Imperial College Press: London, U.K., 2006.

(4) Kalyanasundaram, K. Dye-Sensitized Solar Cells; EPFL Press: Lausanne, 2010

(5) Yella, A.; Lee, H.-W.; Tsao, H. N.; Yi, C.; Chandiran, A. K.; Nazeeruddin, M. K.; Diau, E. W.-G.; Yeh, C.-Y.; Zakeeruddin, S. M.; Grätzel, M. Porphyrin-Sensitized Solar Cells with Cobalt (II/III)Based Redox Electrolyte Exceed 12\% Efficiency. Science 2011, 334, 629-634.

(6) O’Regan, B.; Graetzel, M. A Low-Cost, High-Efficiency Solar Cell Based on Dye-Sensitized Colloidal Titanium Dioxide Films. Nature 1991, 353, 737-740.

(7) Hagfeldt, A.; Boschloo, G.; Sun, L.; Kloo, L.; Pettersson, H. DyeSensitized Solar Cells. Chem. Rev. 2010, 110, 6595-6663.

(8) Bomben, P.; Robson, K.; Koivisto, B. D.; Berlinguette, C. P. Cyclometalated Ruthenium Chromophores for the Dye-Sensitized Solar Cell. Coord. Chem. Rev. 2012, 256, 1438-1450.

(9) Mishra, A.; Fischer, M. K. R.; Bäuerle, P. Metal-Free Organic Dyes for Dye-Sensitized Solar Cells: From Structure: Property Relationships to Design Rules. Angew. Chem., Int. Ed. 2009, 48, 2474-2499.

(10) Martinson, A. B. F.; Hamann, T. W.; Pellin, M. J.; Hupp, J. T. New Architectures for Dye-Sensitized Solar Cells. Chem.-Eur. J. 2008, 14, 4458-4467.

(11) Xie, Y.; Hamann, T. W. Fast Low-Spin Cobalt Complex Redox Shuttles for Dye-Sensitized Solar Cells. J. Phys. Chem. Lett. 2013, 4, $328-332$.

(12) Xu, D.; Zhang, H.; Chen, X.; Yan, F. Imidazolium Functionalized Cobalt Tris(Bipyridyl) Complex Redox Shuttles for High Efficiency Ionic Liquid Electrolyte Dye-Sensitized Solar Cells. J. Mater. Chem. A 2013, 1, 11933-11941.

(13) Kashif, M. K.; Axelson, J. C.; Duffy, N. W.; Forsyth, C. M.; Chang, C. J.; Long, J. R.; Spiccia, L.; Bach, U. A New Direction in DyeSensitized Solar Cells Redox Mediator Development: In Situ FineTuning of the Cobalt(II)/(III) Redox Potential through Lewis Base Interactions. J. Am. Chem. Soc. 2012, 134, 16646-16653.

(14) Li, T. C.; Spokoyny, A. M.; She, C.; Farha, O. K.; Mirkin, C. A.; Marks, T. J.; Hupp, J. T. Ni(III)/(IV) Bis(Dicarbollide) as a Fast, Noncorrosive Redox Shuttle for Dye-Sensitized Solar Cells. J. Am. Chem. Soc. 2010, 132, 4580-4582.

(15) Spokoyny, A. M.; Li, T. C.; Farha, O. K.; Machan, C. W.; She, C.; Stern, C. L.; Marks, T. J.; Hupp, J. T.; Mirkin, C. A. Electronic Tuning of Nickel-Based Bis(Dicarbollide) Redox Shuttles in DyeSensitized Solar Cells. Angew. Chem., Int. Ed. 2010, 49, 5339-5343.

(16) Hamann, T. W. The End of Iodide? Cobalt Complex Redox Shuttles in DSSCs. Dalton Trans. 2012, 41, 3111-3115.

(17) Hamann, T. W.; Farha, O. K.; Hupp, J. T. Outer-Sphere Redox Couples as Shuttles in Dye-Sensitized Solar Cells. Performance Enhancement Based on Photoelectrode Modification Via Atomic Layer Deposition Outer-Sphere Redox Couples as Shuttles in DyeSensitized Solar Cells. Performance Enhancement. J. Phys. Chem. C 2008, 112, 19756-19764.

(18) Son, H.-J.; Wang, X.; Prasittichai, C.; Jeong, N. C.; Aaltonen, T.; Gordon, R. G.; Hupp, J. T. Glass-Encapsulated Light Harvesters: More Efficient Dye-Sensitized Solar Cells by Deposition of Self-Aligned, Conformal, and Self-Limited Silica Layers. J. Am. Chem. Soc. 2012, 134, 9537-9540.

(19) Prasittichai, C.; Hupp, J. T. Surface Modification of $\mathrm{SnO}_{2}$ Photoelectrodes in Dye-Sensitized Solar Cells: Significant Improvements in Photovoltage Via $\mathrm{Al}_{2} \mathrm{O}_{3}$ Atomic Layer Deposition. J. Phys. Chem. Lett. 2010, 1, 1611-1615.
(20) Wu, J.; Lan, Z.; Hao, S.; Li, P.; Lin, J.; Huang, M.; Fang, L.; Huang, Y. Progress on the Electrolytes for DSSCs. Pure Appl. Chem. 2008, 80, 2241-2258.

(21) Snaith, H. J. Estimating the Maximum Attainable Efficiency in Dye-Sensitized Solar Cells. Adv. Funct. Mater. 2010, 20, 13-19.

(22) Hamann, T. W.; Jensen, R. A.; Martinson, A. B. F.; Van Ryswyk, H.; Hupp, J. T. Advancing Beyond Current Generation Dye-Sensitized Solar Cells. Energy Environ. Sci. 2008, 1, 66-78.

(23) For simplicity we ignore the possibility that slow electron transfer kinetics at the counter electrode limit the short-circuit current density.

(24) For simplicity, we ignore the possibility that the forward current density at the photoelectrode is potential-dependent (for example, because of a potential-dependent attenuation of injection efficiency arising from filling of near-band-edge states at very high light intensity).

(25) Listorti, A.; O’Regan, B.; Durrant, J. R. Electron Transfer Dynamics in Dye-Sensitized Solar Cells. Chem. Mater. 2011, 23, 3381-3399.

(26) Schiffmann, F.; Vandevondele, J.; Hutter, J.; Urakawa, A.; Wirz, R.; Baiker, A. An Atomistic Picture of the Regeneration Process in Dye Sensitized Solar Cells. Proc. Natl. Acad. Sci. U.S.A. 2010, 107, 48304833.

(27) Haque, S. A.; Palomares, E.; Cho, B. M.; Green, A. N. M.; Hirata, N.; Klug, D. R; Durrant, J. R. Charge Separation Versus Recombination in Dye-Sensitized Nanocrystalline Solar Cells: The Minimization of Kinetic Redundancy. J. Am. Chem. Soc. 2005, 127, 3456-3462.

(28) Feldt, S. M.; Wang, G.; Boschloo, G.; Hagfeldt, A. Effects of Driving Forces for Recombination and Regeneration on the Photovoltaic Performance of Dye-Sensitized Solar Cells Using Cobalt Polypyridine Redox Couples. J. Phys. Chem. C 2011, 115, 2150021507.

(29) Nazeeruddin, M. K.; Kay, A.; Rodicio, I.; Humphry-Baker, R.; Müller, E.; Liska, P.; Vlachopoulos, N.; Grätzel, M. Conversion of Light to Electricity by Cis- $\mathrm{X}_{2}$ bis $\left(2,2^{\prime}\right.$-Bipyridyl-4,4'-Dicarboxylate)Ruthenium(II) Charge-Transfer Sensitizers $\left(\mathrm{X}=\mathrm{Cl}^{-}, \mathrm{Br}^{-}, \mathrm{I}^{-}, \mathrm{CN}^{-}\right.$, and $\mathrm{SCN}^{-}$) on Nanocrystalline $\mathrm{TiO}_{2}$ Electrodes. J. Am. Chem. Soc. 1993, 115, 6382-6390.

(30) Yu, S.; Ahmadi, S.; Sun, C.; Palmgren, P.; Hennies, F.; Zuleta, M.; Göthelid, M. 4-Tert-Butyl Pyridine Bond Site and Band Bending on $\mathrm{TiO}_{2}$ (110). J. Phys. Chem. C 2010, 114, 2315-2320.

(31) Göthelid, M.; Yu, S.; Ahmadi, S.; Sun, C.; Zuleta, M. StructureDependent 4-Tert-Butyl Pyridine-Induced Band Bending at $\mathrm{TiO}_{2}$ Surfaces. Int. J. Photoenergy 2011, 2011, 1-6.

(32) Kim, J.-Y.; Kim, J. Y.; Lee, D.-K.; Kim, B.; Kim, H.; Ko, M. J. Importance of 4-Tert-Butylpyridine in Electrolyte for Dye-Sensitized Solar Cells Employing $\mathrm{SnO}_{2}$ Electrode. J. Phys. Chem. C 2012, 116, 22759-22766.

(33) Kusama, H.; Orita, H.; Sugihara, H. $\mathrm{TiO}_{2}$ Band Shift by Nitrogen-Containing Heterocycles in Dye-Sensitized Solar Cells: A Periodic Density Functional Theory Study. Langmuir 2008, 24, 44114419.

(34) Liberatore, M.; Burtone, L.; Brown, T. M.; Reale, A.; Di Carlo, A.; Decker, F.; Caramori, S.; Bignozzi, C. A. On the Effect of $\mathrm{Al}_{2} \mathrm{O}_{3}$ Blocking Layer on the Performance of Dye Solar Cells with Cobalt Based Electrolytes. Appl. Phys. Lett. 2009, 94, 173113.

(35) Terranova, U.; Bowler, D. R. Coating $\mathrm{TiO}_{2}$ Anatase by Amorphous $\mathrm{Al}_{2} \mathrm{O}_{3}$ : Effects on Dyes Anchoring through Carboxyl Groups. J. Phys. Chem. C 2012, 116, 4408-4415.

(36) Fan, S.-Q.; Geng, Y.; Kim, C.; Paik, S.; Ko, J. Correlating the Photovoltaic Performance of Alumina Modified Dye-Sensitized Solar Cells with the Properties of Metal-Free Organic Sensitizers. Mater. Chem. Phys. 2012, 132, 943-949.

(37) Yu, H.; Xue, B.; Liu, P.; Qiu, J.; Wen, W.; Zhang, S.; Zhao, H. High-Performance Nanoporous $\mathrm{TiO}_{2} / \mathrm{La}_{2} \mathrm{O}_{3}$ Hybrid Photoanode for Dye-Sensitized Solar Cells. ACS Appl. Mater. Interfaces 2012, 4, 12891294. 
(38) Law, M.; Greene, L. E.; Radenovic, A.; Kuykendall, T.; Liphardt, J.; Yang, P. $\mathrm{ZnO}-\mathrm{Al}_{2} \mathrm{O}_{3}$ and $\mathrm{ZnO}-\mathrm{TiO}_{2}$ Core-Shell Nanowire DyeSensitized Solar Cells. J. Phys. Chem. B 2006, 110, 22652-22663.

(39) Tak Kim, J.; Ho Kim, S. Surface Modification of $\mathrm{TiO}_{2}$ Electrode by Various over-Layer Coatings and $\mathrm{O}_{2}$ Plasma Treatment for Dye Sensitized Solar Cells. Sol. Energy Mater. Sol. Cells 2011, 95, 336-339.

(40) Chandiran, A. K.; Nazeeruddin, M. K.; Grätzel, M. The Role of Insulating Oxides in Blocking the Charge Carrier Recombination in Dye-Sensitized Solar Cells. Adv. Funct. Mater. 2013, 1615-1623.

(41) Antila, L. J.; Heikkilä, M. J.; Aumanen, V.; Kemell, M.; Myllyperkiö, P.; Leskelä, M.; Korppi-Tommola, J. E. I. Suppression of Forward Electron Injection from $\mathrm{Ru}(\mathrm{dcbpy})_{2}(\mathrm{NCS})_{2}$ to Nanocrystalline $\mathrm{TiO}_{2}$ Film as a Result of an Interfacial $\mathrm{Al}_{2} \mathrm{O}_{3}$ Barrier Layer Prepared with Atomic Layer Deposition. J. Phys. Chem. Lett. 2010, 1, 536-539.

(42) Antila, L. J.; Heikkilä, M. J.; Mäkinen, V.; Humalamäki, N.; Laitinen, M.; Linko, V.; Jalkanen, P.; Toppari, J.; Aumanen, V.; Kemell, M.; Myllyperkiö, P.; Honkala, K.; Häkkinen, H.; Leskelä, M.; KorppiTommola, J. E. I. ALD Grown Aluminum Oxide Submonolayers in Dye-Sensitized Solar Cells: The Effect on Interfacial Electron Transfer and Performance. J. Phys. Chem. C 2011, 115, 16720-16729.

(43) Fabregat-Santiago, F.; García-Cañadas, J.; Palomares, E.; Clifford, J. N.; Haque, S. A.; Durrant, J. R.; Garcia-Belmonte, G.; Bisquert, J. The Origin of Slow Electron Recombination Processes in Dye-Sensitized Solar Cells with Alumina Barrier Coatings. J. Appl. Phys. 2004, 96, 6903-6907.

(44) Chandiran, A. K.; Tetreault, N.; Humphry-Baker, R.; Kessler, F.; Baranoff, E.; Yi, C.; Nazeeruddin, M. K.; Grätzel, M. Subnanometer $\mathrm{Ga}_{2} \mathrm{O}_{3}$ Tunnelling Layer by Atomic Layer Deposition to Achieve $1.1 \mathrm{~V}$ Open-Circuit Potential in Dye-Sensitized Solar Cells. Nano Lett. 2012, 12, 3941-3947.

(45) Another approach has been to incorporate long chain alkanes on the periphery of the dye molecules, thereby preventing the close approach of the dye with the semiconductor. In comparison with TBP additives and $\mathrm{Al}_{2} \mathrm{O}_{3}$ coatings, this method will also decrease the rates of dye-regeneration which, depending on the solubility and electrontransfer rates of the redox shuttle, can lead to charge-recombination between the oxidized form of the dye and an electron in the semiconductor. For representative examples of dyes with long alkyl chains and their effect on DSCs containing cobalt redox shuttles, the following two references are recommended: (a) Mosconi, E.; Yum, J.H.; Kessler, F.; Gómez García, C. J.; Zuccaccia, C.; Cinti, A.; Nazeeruddin, M. K.; Grätzel, M.; De Angelis, F. Cobalt Electrolyte/ Dye Interactions in Dye-Sensitized Solar Cells: A Combined Computational and Experimental Study. J. Am. Chem. Soc. 2012, 134, 19438-19453. (b) Feldt, S. M.; Gibson, E. A.; Gabrielsson, E.; Sun, L.; Boschloo, G.; Hagfeldt, A. Design of Organic Dyes and Cobalt Polypyridine Redox Mediators for High-Efficiency Dye-Sensitized Solar Cells. J. Am. Chem. Soc. 2010, 132, 16714-16724.

(46) Nazeeruddin, M. K.; Kay, A.; Rodicio, I.; Humphry-Baker, R.; Muller, E.; Liska, P.; Vlachopoulos, N.; Grätzel, M. Conversion of Light to Electricity by SCN-) on Nanocrystalline Ti02 Electrodes. J. Am. Chem. Soc. 1993, 115, 6382-6390.

(47) Prasittichai, C.; Hupp, J. T. Surface Modification of $\mathrm{SnO}_{2}$ Photoelectrodes in Dye-Sensitized Solar Cells: Significant Improvements in Photovoltage Via $\mathrm{Al}_{2} \mathrm{O}_{3}$ Atomic Layer Deposition. J. Phys. Chem. Lett. 2010, 1, 1611-1615.

(48) Koops, S. E.; O’Regan, B. C.; Barnes, P. R. F.; Durrant, J. R. Parameters Influencing the Efficiency of Electron Injection in DyeSensitized Solar Cells. J. Am. Chem. Soc. 2009, 131, 4808-4818.

(49) Koh, T. M.; Nonomura, K.; Mathews, N.; Hagfeldt, A.; Grätzel, M.; Mhaisalkar, S. G.; Grimsdale, A. C. Influence of 4-TertButylpyridine in DSCs with Co ${ }^{\mathrm{II} / \mathrm{III}}$ Redox Mediator. J. Phys. Chem. C 2013, 117, 15515-15522.

(50) Yang, X.; Zhang, S.; Zhang, K.; Liu, J.; Qin, C.; Chen, H.; Islam, A.; Han, L. Coordinated Shifts of Interfacial Energy Levels: Insight into Electron Injection in Highly Efficient Dye-Sensitized Solar Cells. Energy Environ. Sci. 2013, 6, 3637-3645.
(51) Katz, M. J.; Vermeer, M. J. D.; Farha, O. K.; Pellin, M. J.; Hupp, J. T. Effects of Adsorbed Pyridine Derivatives and Ultrathin AtomicLayer- Deposited Alumina Coatings on the Conduction Band-Edge Energy of $\mathrm{TiO}_{2}$ and on Redox-Shuttle-Derived Dark Currents. Langmuir 2013, 29, 806-814.

(52) At $V_{\text {oc }}$ the forward and reverse currents are equal. In a theoretical device, $J_{\text {dark }}$ at $V_{\mathrm{OC}}$ and $J_{\mathrm{SC}}$ would be theoretically equal.

(53) Barnes, P. R. F.; Anderson, A. Y.; Koops, S. E.; Durrant, J. R.; O'Regan, B. C. Electron Injection Efficiency and Diffusion Length in Dye-Sensitized Solar Cells Derived from Incident Photon Conversion Efficiency Measurements. J. Phys. Chem. C 2009, 113, 1126-1136.

(54) While the departure of the ratio from unity suggests a chargecollection length that does not span the full electrode, we have not accounted for back-side losses due to competitive light absorption by the platinum-coated counter electrode and by triiodide in the solution beyond electrodes.

(55) On the basis of the similar difference in front-side/back-side IPCE differences in an $\mathrm{I}_{3}^{-} / \mathrm{I}^{-}$-containing DSC, the remaining frontside/back-side differeces in $\mathrm{Co}($ phen $) 3^{3+/ 2+}$ are primarily due to competitive light absorption by the platinum counter electrode and the electrolyte solution.

(56) Nazeeruddin, M. K.; Baranoff, E.; Grätzel, M. Dye-Sensitized Solar Cells: A Brief Overview. Sol. Energy 2011, 85, 1172-1178.

(57) Bertoluzzi, L.; Ma, S. On the Methods of Calculation of the Charge Collection Efficiency of Dye Sensitized Solar Cells. Phys. Chem. Chem. Phys. 2013, 15, 4283-4285.

(58) Recall that for small changes in driving force for electrontransfer reactions in the Marcus normal region, theory promises exponential modulations of rates of electron transfer. In the lowdriving-force limit, a ca. $120 \mathrm{meV}$ change in reaction free-energy should engender a factor of 10 change in rate ET constant.

(59) Alumina-induced diminution of charge-injection yields could conceivably arise not only from changes in driving force but also from changes in dye/electrode electronic coupling.

(60) Open-circuit photovoltage decay reports on back-ET to both the oxidized dye and the oxidized shuttle, while open-circuit voltage decay report on back-ET to only the shuttle. A comparison of these two plots illustrates the effect of the oxidized dye on the electron survival times; similar plots indicate no significant contribution from the oxidized dye while differing plots (often at high voltages/early decay times) indicate that regeneration is insufficent and thus recombination becomes problematic. 